\title{
NOTAS SOBRE O STATUS DE MULHERES NEGRAS NO PÓS-ABOLIC̣ÃO EM BARBADOS A PARTIR DE UM FEMICÍDIO
}

Elaine

\section{ROCHA}

(D) elaine.rocha@cavehill.uwi.edu

University of the West

Indies at Cave Hill

Bridgetown, Barbados

Notes on the Status of Black Women in Post-Abolition Barbados

based on a case of Femicide

\section{RESUMO}

Este estudo propõe-se a discutir o femicídio, a partir do caso do assassinato de Millicent Gittens em Barbados, em 1916. Utiliza-se o termo femicídio conforme proposto por Diane Russell, como o crime perpetrado por homens contra mulheres, cuja motivação central é a imposição da hegemonia masculina. O baixo estatus da população feminina pobre e negra no pós-abolição em Barbados é analisado com base na produção acadêmica brasileira e estrangeira sobre estudos de gênero, de Bell Hooks a Olívia Gomes da Cunha, e no pensamento de autores como Pierre Bourdieu e Michel Foucault sobre as relações de poder. A base documental desta pesquisa é formada por documentos primários como jornais, relatórios e documentos oficiais sobre o crime e sobre as condições de vida em Barbados no pós-abolição. Ao focalizar este estudo na ilha de Barbados, é possível estabelecer aquela sociedade como um "estudo de caso", por tratar-se de um grupo relativamente isolado e de uma população que hoje se encontra em torno de 280 mil pessoas. Em 1916 a população total da ilha era de aproximadamente 100 mil habitantes, naquele ano apenas dois assassinatos foram registrados em Barbados, ambos tendo mulheres negras como vítimas de seus parceiros íntimos.

Palavras-chave: femicidio, pós-abolição, Barbados, feminismo negro, gênero.

\begin{abstract}
This study proposes to discuss femicide in the case of the killing of Millicent Gittens, murdered in Barbados in 1916. The term femicide as proposed by Diane Russell is used as the crime perpetrated by men against women whose central motivation is the imposition of male hegemony. The low status of the poor and black female population in post-abolition in Barbados is analyzed based on the Brazilian and foreign academic production on gender studies, from Bell Hooks to Olívia Gomes da Cunha, and on the thinking of authors such as Pierre Bourdieu and Michel Foucault on power relations. The basis for this research is made up of primary documents such as newspapers, reports and official documents on crime and on the conditions of life in Barbados in postabolition. By focusing this study on the island of Barbados, it is possible to establish that society as a "case study", because it is a relatively isolated group and a population that today is around 280 thousand people. In 1916 the total population of the island was approximately 100 thousand inhabitants; that year two murders were committed, both against Black women.
\end{abstract}

Keywords: femicide, post abolition, Barbados, black feminism, genre. 
somebody/anybody sing a black girl's song bring her out

to know herself to know you

but sing her rhythms caring/struggle/hard times

sing her song of life she's been dead so long closed in silence so long she doesn't know the sound of her own voice her infinite beauty she's half-notes scattered without rhythm/ no tune sing her sighs

sing the song of her possibilities sing a righteous gospel let her be born let her be born

\& handled warmly. (SHANGE, 2010, p. 18)

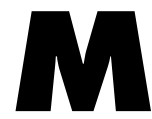
illie nasceu por volta de 1894, na ilha de Barbados, batizada como Millicent Gittens. Sobre ela não há biografia; a historiografia nunca tratou de sua vida. Não sabemos quem foi sua mãe ou seu pai. Sabemos que Millie era negra, trabalhava como doméstica e vivia num quartinho no fundo da casa de seus patrões. Tinha uma irmã que trabalhava como vendedora ambulante e vivia na periferia da cidade de Bridgetown, e um filho que, por não ter como cuidar, deixava ao encargo de uma senhora, a quem pagava pelo trabalho. Na primeira noite de dezembro de 1916, uma sexta feira de lua cheia, Millie foi assassinada por seu namorado, James, com golpes de faca no pescoço. Seu corpo foi enrolado a uma pedra com arame, e atirado num pequeno reservatório cheio de água. Uma espécie de tanque abandonado, que servia para destilar petróleo bruto, utilizado para iluminação.

A tragédia de sua morte não consta da historiografia barbadiana, mas o cancioneiro popular preservou a indignação do povo ao eternizar a morte de Millie numa canção que virou parte do folclore da pequena ilha, viajando com os emigrantes e chegando a Cuba, Estados Unidos, Costa Rica e Inglaterra. Até hoje, comunidades de imigrantes barbadianos e seus descendentes, ao celebrar a terra natal, cantam, entre outras músicas, aquela que narra a estória de uma mulher que sonhava em se mudar para o Brasil. "Millie Gone to Brazil", é uma canção de autoria desconhecida, conhecida por quase todos na ilha de Barbados; professores ensinam as crianças nas escolas a cantar essa que se tornou parte da cultura nacional. 
Millie gone to Brazil Oh Lawd, poor Millie

Millie gone to Brazil

Oh Lawd, poor Millie

Wid de wire wrap round she waist And the razor cut up she face Wid de wire wrap round she waist And the razor cut up she face

Millie down in the well

Oh Lawd, poor Millie

Millie down in the well

Oh Lawd, poor Millie

Wid de wire wrap round she waist And the razor cut up she face

Wid de wire wrap round she waist And the razor cut up she face ${ }^{1}$

Este artigo se propõe a analisar o caso do assassinato de Millicent Gittens por seu namorado James Bayley, em Barbados como paradigma para se entender o status social das mulheres negras no pós-abolição, considerando as relações de gênero e o panorama sócio-econômico daquela sociedade no pós-abolição. As questões primordiais que guiam a proposta analítica são, em primeiro lugar, a condição de subalternidade da vítima, e a presunção do assassino, de que seu papel como homem Ihe concedia direitos de vida e morte sobre sua parceira íntima.

\section{A colônia britânica de Barbados}

Barbados é uma ilha localizada no extremo leste do arquipélago caribenho, com um território que totaliza 432 km², $34 \mathrm{~km}$ de comprimento por $23 \mathrm{~km}$ de largura. Foi colonizada por ingleses, que controlaram o país até 1966. A população, de 280 mil habitantes, é composta majoritariamente por descendentes de africanos (95\%), uma minoria de descendentes de europeus (3\%) e de asiáticos originários da Índia (2\%).

A relativa homogeneidade da população e o tamanho do país, fazem da sociedade o modelo ideal para estudos de caso. Ainda que não seja uma abordagem moderna, estando em uso desde o início do século XX, o método de pesquisa histórica baseado no estudo de casos, ou case history, permite ao historiador uma análise mais abrangente e profunda de um fenômeno histórico, conforme defendeu Katharine Jocher, há quase um século (JOSHER, 1928). Dessa forma, um fato histórico, como um crime, pode ser análisado extensiva e intensivamente, considerando o contexto e o processo histórico, a composição demográfica, características do grupo social atingido e fatores como economia, educação e cultura.

De acordo com o relatório do Banco Interamericano de Desenvolvimento para o ano de 2015, Barbados apresenta um dos mais baixos percentuais de crimes de morte deste continente. Entre 2000 e 2015, a média anual de homicídio esteve por volta de 
10 assassinatos para cada 100 mil habitantes; isto num país que tem 280 mil habitantes. A incidência de outros crimes, como roubo e estupro, é também considerada muito baixa (BAILEY, 2016). Contudo, o Tribunal Regional do Caribe sobre Violência contra Mulheres denunciou, em 2001, a alta incidência de crimes contra mulheres e meninas, que são a maioria das vítimas da violência doméstica. Ainda que Barbados não esteja entre os países com maior incidência na região, o relatório apontou para uma cultura de silêncio em torno da violência de gênero, reforçada pela cultura caribenha, que naturaliza os abusos físicos, sexuais e psicológicos que mulheres e meninas sofrem nas mãos de parceiros e familiares. ${ }^{2}$

A população barbadiana nas primeiras décadas do século XX era de aproximadamente 100 mil habitantes. A maioria situada na zona rural e vinculada à economia da cana de açúcar, produto central da economia colonial desde o século XVII. O crescimento populacional naquele período era limitado por fatores econômicos, visto que as crises econômicas geradas por quedas dos preços do açúcar ou por desastres naturais como secas, tempestades ou furacões, resultavam em desemprego e êxodo rural ${ }^{3}$, impulsionavam a emigração masculina e provocavam o aumento da mortalidade infantil devido à pobreza (ROCHA e ALLEYNE, 2012; BARROS, 2014).

Nos relatórios anuais produzidos pelo governo colonial para Barbados, os dados indicam uma criminalidade bastante baixa. Entre 1902 e 1909 foram registrados 20 crimes de morte; entre 1910 e 1920 encontramos 21 crimes de morte. De acordo com os registros oficiais, também eram poucos os casos estupro - entre dois e três por ano, para o período entre 1910 e 1920. Por outro lado, a alta incidência de nascimentos classificados como ilegítimos, ou seja, filhos de mães solteiras, pode ser um indicador de que os números de violência sexual eram elevados, porém muitos casos não eram denunciados. ${ }^{4}$ Em 1916 aconteceram apenas dois crimes de morte, ambos contra mulheres negras solteiras, uma delas era Millicent Gittens, a Millie da canção popular.

\section{Mulheres Negras e Femicídio, histórias ainda pouco exploradas}

Em 1976, no Tribunal Internacional de Crimes contra Mulheres, Diana Russell propôs o uso do termo femicídio para denunciar o assassinato de mulheres diferenciando esse tipo de crime do homicídio. Russell explica que o femicídio é o assassinado de mulheres por homens, fundamentado na misoginia e, portanto crimes políticos, ou seja, de imposição de poder.

Nós temos que reconhecer que muitos homicídios são de fato femicídios. Temos que reconhecer políticas sexuais dos assassinatos. Desde a queima de bruxas, no passado, até a mais recente costume generalizado do infanticídio feminino, até a morte de mulheres por "honra". Reconhecemos que o femicídio vem acontecendo há um longo tempo. Mas porque envolve meras fêmeas, não havia termo próprio para isso antes do termo femicídio ser forjado (RUSSELL, 2012). 
Anos depois, Marcela Lagarde passou a defender o uso do termo feminicídio em referência à realidade da América Latina, onde os assassinatos de mulheres não são devidamente punidos, em contraste à definição de Russell que se refere ao ato de assassinar mulheres.

Cuando traduje el texto de Diana Russell, me tomé la libertad
de modificar el concepto, ella lo llama femicide y entonces
yo lo traduje desde hace ya varios años como feminicidio,
precisamente para que no fuera a confundirse en castellano
como femicidio u homicidio femenino; no, yo quería que fuera
un concepto claro, distinto, para que entonces viniera junto con
todo el contenido del concepto, que es, como ya lo expliqué,
muy complejo. (LAGARDE, 2006, p. 221).

Nesta pesquisa, utilizo a definição original, de Russell, não somente porque o crime contra Millie foi punido (ainda que analise outros casos, com diferente desfecho), mas porque o foco da pesquisa é o crime de morte perpetrado por um homem contra uma mulher, motivado pela intenção de submetê-la à sua autoridade. Para mim, o termo femicídio é mais adequado, por se tratar do ato de um "macho" matar uma "femea", enquanto feminicído me parece uma derivação de feminino, ou seja "matar o feminino", que neste caso teria uma conotoção muito mais subjetiva. Em outras palavras, a explicação oferecida por Lagarde, ainda que real, não justifica uma alteração do termo femicídio, que é utilizado em regiões fora da América Latina, onde também o assassinato de mulheres raramente é punido com a mesma frequência e severidade como é quando a vítima é homem. Conforme Russell argumenta, "a definição de um termo não deve ser determinada pelo resultado do fenômeno ao qual o termo se aplica" (RUSSELL, 2012, p. 3).

No Brasil, o femicídio vem sendo tema de estudos esparsos dentro da história. Trabalhos como os de Mariza Correa (1983), ainda que no campo da antropologia, foram pioneiros nesse tema, ao discutir os papéis de gênero nos crimes passionais na cidade de Campinas entre 1952 e 1972, influenciando estudos e análises posteriores. Dentro da história, ao final dos anos 80, Susan Besse (1989) discutiu assassinatos de mulheres no Brasil entre 1910 e 1940; Andrea Borelli (1997) estudou crimes passionais na cidade de São Paulo entre 1920 e 1930 em sua dissertação de mestrado; Magali Engel (2000) elaborou pesquisa com enfoque nos crimes de paixão, trabalhando com questões de gênero tanto para assassinatos cometidos por homens e por mulheres; e Maria Clarice de Souza (2011) analisou crimes passionais ocorridos em Montes Claros, MG, entre 1985 e 1993.

Em outras pesquisas, crimes de morte contra mulheres surgem como parte de pesquisas sobre a violência de gênero, ou mesmo sobre a construção dos papéis de gênero na sociedade brasileira. Ainda que não se duvide da importância de tais estudos, essa realidade comprova a lacuna nos estudos específicos sobre o femicídio dentro do campo disciplinar da história. 
De forma ainda mais intensa, pode-se apontar para a escassez de estudos históricos sobre a violência de gênero e o femicídio dentro de um recorte racial, nacional ou étnico. Joan Scott (1999), chama a atenção para a multiplicidade de facetas nos estudos de gênero, na edição revisada de seu clássico, Gender and the Politics of History, alertando contra as generalizações das análises e para a necessidade de estudos específicos que atentem para a construção dos significados de gênero dentro de contextos específicos. Em trabalho mais recente, a mesma autora dedica-se a explorar o discurso político e etnocêntrico por trás da decisão do governo francês em proibir mulheres muçulmanas de usarem o véu em escolas públicas, estabelecendo uma intersecção de gênero e imperialismo em uma análise que tem como cerne a questão do poder (SCOTT, 2007). Rebecca Edwards (2012) segue a mesma premissa, ao afirmar que as questões de gênero e a opressão das mulheres não podem ser vistas fora do emaranhado de outras formas de opressão, especialmente das tensões raciais.

O femicídio, também denominado honour killing (crimes de honra), tem sido alvo de estudos nas áreas de sociologia, nos estudos de comunidades de imigrantes e ainda timidamente na história. Em geral, tais trabalhos procuram examinar a violência contra mulheres e crianças, e recentemente contra homossexuais, fundamentadas em filiação religiosa e em hierarquias patriarcais de culturas não-cristãs. Liat Kozma (2011) realizou um estudo sobre tais crimes de honra no Egito, dentro de um enfoque que examina as normas patriarcais, o impacto das novas leis que viriam a regulamentar a sociedade egípcia no século XIX e o impacto da dominação inglesa ao final daquele século. Como resultado, o livro constrói um retrato da sociedade egípcia naquele período, em torno das práticas de controle e dominação do corpo feminino. Estudos nos campos da sociologia e antropologia sobre o sul da Ásia e a violência imposta sobre as mulheres dentro da família, comunidade ou por disputas políticas entre diferentes grupos, têm lançado luzes sobre contextos que, por muito tempo, têm se mantido invisíveis por pesquisadores ocidentais.

A violência contra as mulheres, desde mortes a dotes e estupros a tradições tribais, como karo kari, é justificada em nome da tradição. Estamos interessados em entender formas particulares de violência "patológica" que as mulheres experimentam por meio de sua significação como repositórios de tradição e cultura, e sofrem nas mãos de suas comunidades "próprias" ou rivais (BANERJEE et al., 2004, p. 130). ${ }^{5}$

No Brasil, ainda que a violência contra mulheres negras e indígenas seja frequentemente denunciada por organizações feministas e de direitos humanos, o tema ainda não tem visibilidade na historiografia do Brasil. Quando explorado, em geral, o tema restringe-se aos limites temporais da história colonial e da escravidão, centralizando a análise nas relações interraciais, sobretudo na violência de homens brancos contra mulheres negras e indígenas. $O$ crescimento gradativo da atuação de historiadores e historiadoras negras, notada principalmente a partir dos anos 90 , tem influenciado grandemente a história dos negros no Brasil e na última década 
passou a incorporar temas dedicados à intersecção entre gênero e raça, ainda que timidamente e ainda limitado à moldura temporal da escravidão.

Alguns trabalhos enfocam as camadas mais pobres da população, na qual a população negra se inclui, sem referir-se a filiações raciais. Alguns discutem a violência de gênero enfocando no contexto socioeconômico e nas limitações que a condição de subalternidade inferia ao homem pobre, impedindo-o de preencher a expectativa de dominância que a sociedade atribuía ao homem em relação à mulheres (SOIHET, 2002; ABREU, 2003; CHALHOUB, 1986).

Algumas biografias de mulheres negras revelam elementos indicativos da violência de gênero, principalmente quando analisa a exclusão econômica, a pobreza, o abandono materno e as cadeias de subalternidade. Vez por outra, os trabalhos falam sobre a violência física e o abuso de mulheres negras por seus parceiros e familiares, mas não como parte central da análise, como na obra autobiográfica de Carolina Maria de Jesus (2010).

Mais evidências sobre a violência contra mulheres negras são encontradas na literatura. Desde os anos 40, os romances de Jorge Amado, como Jubiabá (1978), Tereza Batista Cansada de Guerra (1978) e Tieta do Agreste (1978), falam sobre o estupro de jovens negras, a violência contra mulheres nas mãos de parceiros íntimos ou de pretendentes e sobre a violência doméstica, ainda que não necessariamente problematize o tema. Já no novo milênio, Conceição Evaristo publicou Ponciá Vicêncio (2018), no qual a violência de gênero assume papel mais relevante.

As músicas populares, no entanto, estão repletas de referências à violência física contra a mulher, perpetuada por seus parceiros e amantes. O tema da mulher que merece apanhar surge já nas primeiras gravações e é muito presente nos sambas, passando pela música brega e chegando aos dias de hoje no funk. No caso da música Millie Gone to Brazil, especula-se sobre a mesma familiaridade do tema da violência de gênero na música do Caribe inglês, o que explicaria a naturalidade com que a sociedade utiliza a canção como parte de seu repertório cultural sem problematizar a tragédia.

Nos Estados Unidos a historiografia sobre a experiência negra apresenta uma concentração na oposição racial brancos contra negros, numa clara posição de denúncia e resistência ao racismo violento e institucionalizado. Trabalhos como o de Danielle McGuire (2010), analisando os casos judiciais contra homens brancos que estupraram mulheres negras entre 1940 e os anos 70, são importantes por darem visibilidade à violência histórica contra essas mulheres, em contextos nos quais elas são alvo de ataques sexuais não apenas por serem mulheres, mas por serem mulheres negras. Mas é no campo da literatura negra, como na obra de Alice Walker (1992) e nas letras da música negra - particularmente os blues - que se encontram inúmeras evidências de violência sexual e abusos físicos contra a mulher negra por seu parceiro negro.

Em geral, questão da violência entre parceiros íntimos pertencentes à população negra continua sendo tabu, não porque não exista, mas porque a sua denúncia é vista 
como uma forma de enfraquecimento da luta dos negros por igualdade e direitos civis. Considerada como uma das fundadoras do Feminismo Radical Negro, Bell Hooks (1981) expõe a desvalorização da mulher negra na sociedade em geral, sobretudo pelo homem negro. A autora vai adiante, denunciando que parte da plataforma política de líderes negros do século $X X$ é o direito patriarcal do homem negro ser o provedor da família e de ser considerado superior à sua mulher, renegando a possibilidade de igualdade dos sexos.

Roberta Villalón (2010), Patricia Hill Collins (2000), Sandra Hartman (1987) e Bonnie Thornton Dill (1987) discutem a importância de substituir a abordagem universalizante da violência de gênero, por estudos que considerem a intersecção das variantes raça, etnia, contexto socioeconômico, religião, orientação política, orientação sexual e estatus de imigrantes: nacionalidade, língua, legalidade, integração social, além das manifestações culturais que determinam os papéis, direitos e deveres de gênero. Em suma, as autoras enfatizam a importância de se entender o fenômeno da violência dentro de seu contexto, de forma a esclarecer sua manifestação.

A historiadora Jamaicana Erna Brodber (2004) refere-se ao status inferior, equivalente ao da criança, que as mulheres caribenhas negras estavam submetidas. Examinando a sociedade Jamaicana entre 1907 e 1914, ela cita o caso de Meme, de 20 anos de idade, que foi esbofeteada na rua, por um homem que "nem era de sua família", pelo delito de estar assobiando em público, algo condenado pelos costumes daquela sociedade, que ditava que apenas homens poderiam assobiar. A agressão física, longe de provocar revolta na vítima, fez com que ela imediatamente reconhecesse o delito e se desculpasse com o agressor.

Em Barbados, o tema é novo na historiografia, tendo sido estudado como problema contemporâneo por pesquisadores das ciências sociais, seguindo as políticas de combate à violência doméstica e de gênero. Um estudo histórico foi feito por Hillary Beckles (2000), sobre a violência e a exploração sexual da mulher escrava, nas mãos de senhores brancos. A questão da violência entre casais negros, no entanto, é um fenômeno que atravessa o século $X X$ e entra no século $X X I$, conforme constatado no exame dos jornais do período. Seu entendimento, a partir de exame das relações e das condições sócioeconômicas do pós-abolição pode lançar alguma luz para se entender o problema na atualidade.

\section{Crônica de uma morte anunciada}

Na manhã de sábado, no dia dois de dezembro de 1916, a esposa do diretor de uma escola primária localizada poucos quilômetros fora de Bridgetown, percebeu que sua empregada doméstica não havia dormido no quartinho localizado no quintal da casa. Logo começaram as buscas, pela vizinhança e entre parentes e conhecidos. A jovem negra, de 22 anos, conhecida como Millie, trabalhava e vivia na casa do "mestre escola" havia quase um ano. Ela normalmente saía aos domingos, e costumava avisar a patroa se fosse dormir fora de casa. Sua irmã, única parente adulta conhecida, vivia nos arredores de Bridgetown, onde trabalhava como vendedora ambulante, Millie tinha 
um filho pequeno, cuja idade e paternidade não foi declarada, e que vivia com uma senhora a quem Millie pagava pelo serviço. Entre as pessoas mais próximas estava também James Bailey, que namorava a vítima há aproximadamente nove meses, e que várias pessoas tinham visto com Millie na sexta feira. Enquanto as buscas continuavam, James que dizia a todos que Millie havia tomado um navio para o Brasil.

Contra a explicação apresentada por James para o desaparecimento de Millie, havia algumas evidências: as poucas roupas e um par de alpargatas continuavam no quartinho, e o salário a ela devido não foi reclamado. Alem disso, a mulher encarregada de cuidar de seu filho não sabia da viagem, Millie não viera se despedir da criança. Sua irmã afirmava que Millie nunca teria partido sem se despedir, que teria tomado medidas para os cuidados do filho. Acima de tudo, havia o fato de que nenhum navio havia saído do porto entre os dias $1^{\circ}$ e 3 de dezembro em direção ao Brasil.

Uma equipe de busca foi improvisada com moradores do bairro, amigos, conhecidos e curiosos. A patroa chamou a polícia, que iniciou as investigações no sábado à noite. James fazia parte do grupo de busca. No domingo de manhã, o corpo de Millie foi encontrado a aproximadamente um quilômetro de distância da casa onde vivia, dentro de um reservatório abandonado, à beira da praia, a poucos metros de um lugarejo de pescadores pobres. Uma pessoa havia informado a polícia que vira manchas de sangue no caminho que levava ao reservatório. O sangue ao pé do reservatório levantou a suspeita. Inspecionado, foi resgatado da água o corpo sem vida de uma mulher negra, completamente vestido. O cadáver exibia cortes profundos no pescoço, e estava enrolado com um arame que segurava uma grande pedra, usada para manter o corpo submerso.

Uma pequena multidão de quase setenta pessoas acompanhou a retirada do corpo de dentro do tanque. James teria gritado entre lágrimas, quando viu o corpo: "Oh, Senhor! Olha pra Millie!” Em seguida, ele percebeu olhares e palavras acusadoras em sua direção, e tentou fugir, mas foi alcançado logo. Ao ser imobilizado, gritou: "Oh, Millie, eu amava tanto essa menina!"6

No ano seguinte o caso foi destacado no Report of the Police Force of the Colony for 1917. ${ }^{7}$ O caso foi também discutido em reunião na Assembleia de 3 de abril de 1917, que destacou que houve dois assassinatos em 1916, nos dois casos as vítimas eram mulheres que trabalhavam como domestic servants. A primeira era Helen Boxill, negra, solteira, de 38 anos, que teve o crânio quebrado com uma pedra, em seu quartinho, no quintal da fazenda onde trabalhava, na noite de 13 de agosto de 1916. O principal suspeito era Fitzherbert Simpson, um ex-namorado, chofer na mesma família, que se ressentia por ser rejeitado pela vítima. Segundo testemunhas, Helen estava indo para um tipo de quermesse na igreja local com as amigas, quando Fitzherbert a chamou para conversar. Ela aceitou e o levou para seu quartinho, dizendo às amigas que as encontraria em seguida. Seu corpo foi encontrado no mesmo quartinho, horas mais tarde, quando as amigas voltaram para busca-la, vendo que se atrasava. O ex-namorado, era o chofer da família proprietária, para a qual Helen trabalhava como doméstica. Apresentou advogado e, mesmo levado a julgamento, foi absolvido por ausência 
de provas. O testemunho das companheiras de Helen não teria sido suficiente para comprometer aquele que pertencia a uma classe superior. ${ }^{8}$ Os dois casos apareceram no diário oficial da colônia.

O outro caso foi o de outra jovem mulher, chamada Millicent Gittens, também uma empregada doméstica, cuja garganta foi cortada na noite de primeiro de dezembro de 1916, perto da praia da Pedra do Morcego, no distrito de Black Rock, Saint Michael, e seu corpo jogado num tanque de água, onde foi descoberto na manhã do $3^{\circ}$ dia de dezembro. ${ }^{9}$

A notícia sobre o assassinato de Millie apareceu no jornal local The Agricultural Reporter nos dias que se seguiram ao crime e alguns meses depois, quando houve o julgamento. O estilo de reportagem da época e a raridade do acontecimento levaram a um relato detalhado dos acontecimentos, inclusive com dados sobre o inquérito. Segundo o jornal, após a confirmação da identidade da vítima e o reconhecimento de James como principal suspeito, testemunhas se apresentaram para falar de seu encontro com o casal, dia em que Millie desapareceu.

Segundo o jornal, Ernest Burnett, assistente de engenheiro na destilaria de rum onde James trabalhava, vira o suspeito na manhã do dia $1^{\circ}$ de dezembro, por volta das seis da manhã, conversaram um pouco, e James - sem ser perguntado - disse a Ernest que Millie estava de partida para o Brasil, disse ainda que se conseguisse atrair a namorada para uma área isolada, gostaria de lhe dar uma grande surra. Na mesma manhã, um pouco mais tarde, Irvine Robinson, um velho pescador daquela área, viu Millie e James perto da área onde estavam os reservatórios abandonados. Perguntara a James se ele não havia ido trabalhar, e o jovem disse que não. O pescador teria feito então uma brincadeira, indicando que os dois estavam "tirando umas férias", ao que James teria respondido muito sério que naquela noite ele iria enfiar uma faca na garganta da mulher, chegou mesmo a mostrar a faca que trazia no bolso da blusa. Irvine continuou seu testemunho, referindo à falta de reação de Millie: "Ela estava de pé ao seu lado, e ouviu quando ele disse isso. Não disse nada, apenas baixou a cabeça e descansou o queixo na mão"10. Por volta de 12:30 e 13 horas da tarde, Frances Hunte, uma lavadeira que morava na região, disse que James apareceu em seu quintal e lhe pediu um pedaço de arame galvanizado, que ela mantinha para pendurar sua roupa. Frances havia enrolado e posto o arame em cima do chiqueiro, porque o poste que segurava o varal havia caído, e além do mais, ela preferia usar arame farpado, para não ter que usar prendedores para manter as roupas estendidas. Muito ocupada com seus afazeres, ela teria dito a James que podia pegar o arame que precisasse, mas ela não podia parar para ajudá-lo. Aquele foi o arame encontrado com o cadáver. ${ }^{11}$ Um cocheiro negro de aproximadamente 50 anos de idade, chamado Joseph Jackman, testemunhou que, ao entardecer da sexta-feira, Millie encontrou-se com James, que conversava com Joseph, debaixo de uma paineira próxima à casa onde ela vivia. Em seu testemunho, Jackman afirmou ter presenciado uma discussão entre os dois algumas semanas antes, ocasião em que James acusou a namorada de estar gastando dinheiro dado por outro homem, Millie negou que isso fosse verdade. Joseph testemunhou que no dia em questão, estavam sob a paineira quando Millie 
apareceu, por volta das 7 da noite, usando uma saia preta, blusa branca, um colete de cor escura e um pequeno chapéu. James estava de pé perto da árvore, descalço, com calças de cor escura, camisa e um paletó também escuro. Ao vê-la, James teria dito "Millie, eu vou te dar o que eu te prometi. Vem, vamos caminhar pela estrada, para eu te dar". Ela então perguntou por que ele não mandou (o presente?) para ela. E ele respondeu: "Millie, você me disse que quando eu tivesse algo para te dar, para não entregar a ninguém mais". Dali, os três resolveram caminhar até Bridgetown, uma caminhada de aproximadamente 7 quilômetros. Porém, após caminhar por uns 500 metros, Joseph desistiu do plano e, alegando cansaço, retirou-se para sua casa. "Antes de eu me separar deles, o acusado me disse que eles estavam indo para a cidade, e que Millie não retornaria. Ele disse que eu não a veria mais depois daquela noite". Em seu testemunho, o cocheiro disse que Millie seguia com os dois homens muito calada, e que mais de uma vez James teria dito ao amigo que iria matar a namorada naquela noite. Quando Joseph já estava em sua casa há quase três horas, James foi visitá-lo, dizendo que Millie havia embarcado num navio para o Brasil às 10 da noite, na companhia de outro homem. Joseph Jackman testemunhou que James não parecia estar embriagado, em nenhum momento naquela noite da tragédia. ${ }^{12}$

As evidências apontam não apenas para um crime planejado em detalhes: arma, local, forma de esconder o corpo, desculpa para o desaparecimento da namorada; mas para um crime anunciado à sua vítima e a outros que estavam à sua volta. No entanto, de acordo com o inquérito, nenhuma das testemunhas, nem a vítima, tentaram impedir a tragédia.

Joseph Gibson testemunhou que estava em sua casa quando viu James passar pelo caminho que levava à área dos tanques, entre 7 e 9 da noite da sexta-feira. Millie caminhava silenciosamente na frente, com as duas mãos às costas, atrás dela, bem próximo, caminhava James, também em silêncio. Disse que tinha certeza do que vira, porque era lua cheia e a noite estava muito clara.

\section{Quem cala consente ou aceita a sentença?}

O que marca a leitura dos relatos, é a persistência de James ao planejar o crime e o silêncio de Millie, que não pediu ajuda a ninguém, em nenhum momento. Ao contrário, parecia caminhar sem resistir em direção à própria morte.

Estudos atuais sobre mulheres envolvidas em relações de abuso com parceiros íntimos apontam para um padrão de tolerância desse abuso por parte das vítimas, que apresentam características de baixa autoestima e depressão. Além disso, a relação conflituosa inclui abuso verbal, emocional, físico e sexual. Muitas vezes a vítima sai de um relacionamento abusivo para entrar em outro. $O$ fato de James anunciar ao amigo que pretendia dar uma grande surra em Millie - e de que isso não foi em nenhum momento contestado pelo ouvinte - aponta para a aceitação social da violência de gênero, fato que ainda hoje é denunciado em campanhas contra a violência doméstica no país. 
Analisando o crime e a violência em Barbados naquele início do século, relatórios de autoridades apontam para uma crise social e econômica em Barbados entre 1840 e 1940. A pobreza e a falta de opções para moradia, levava à aglomeração em determinados pontos da cidade, que resultavam em promiscuidade e violência. Havia grande preocupação com a alta incidência de nascimentos ilegítimos e para as condições de extrema pobreza de mães que, sem condições para cuidar de seus filhos, os deixavam aos cuidados de outros, ou muitas vezes sozinhos ou com irmãos um pouco mais velhos. Examinando os relatórios das autoridades coloniais para fins do século XIX e início do XX, Juanita de Barros (2014) aponta para uma condenação moral dos administradores para com a população negra, a quem atribuem a culpa pela miséria e pelas epidemias. Segundo Barros, os governantes preocupavam-se com o baixo índice de casamentos entre os pobres, ao lado de um índice muito alto de nascimentos ilegítimos. Dados estatísticos apontam para uma taxa de mortalidade acima de $25 \%$ entre os nascidos no período entre 1895-1900, dentre os mortos, mais de 70\% eram ilegítimos, dado verificado também no ano de 1913 (APPLEWHAITE, 2007). As condições de pobreza de Millie e de sua irmã Clementina indicam que há uma grande probabilidade destas serem parte de um ciclo de pobreza e ilegitimidade. Tal pobreza impedia a família de viver junto, contudo, Clementina testemunhou que via Millie com frequência, enquanto que a patroa de Millie indicou que o filho da vítima era cuidado por uma mulher que vivia do outro lado da rua, perto da casa em que Millie vivia e trabalhava. Isso indica que, apesar das limitacões econômicas, laços de família eram mantidos e de alguma maneira havia a preocupação de cuidar dos entes próximos. Não se pode provar que Millie tinha vivido uma relação abusiva anterior ao seu envolvimento com James, apesar da maternidade fora do casamento.É possível que ela tenha não apenas vivido relacionamentos abusivos, mas testemunhado abusos contra outras mulheres, o que a levava a aceitar a subalternidade de seu sexo.

A situação de exploração e subordinação extrema das mulheres negras desde o período escravista vem sendo apontada em vários estudos. Sandra Lauderdale Graham (2002) e Hebe Mattos de Castro (1995), demonstraram em sua pesquisa que a condição de subalternidade da mulher negra a colocava à mercê de abusos dos patrões, das patroas e de parceiros do mesmo sexo e da mesma condição. A violência contra mulheres e meninas negras incluía como algozes seus próprios familiares, conforme indicou Tara Inniss (2014; 2008), ao examinar o caso de Barbados. Nos Estados Unidos, Emily West é uma das poucas historiadoras a discutir a prevalência da violência contra a mulher negra, apontando que o homem negro escravizado, ainda que vítima do sistema escravista, perpetuou os abusos físicos e sexuais contra as mulheres negras escravizadas (2018).

A historiografia caribenha mostra que a abolição não trouxe consigo uma alteração radical no status das mulheres negras. Beckles (2004) aponta para uma preocupação das autoridades em relação à aglomeração urbana que se desenvolvera em torno de Bridgetown já em 1838, relacionando-a aos slums. A pressão econômica e o controle dos empregadores sobre seus empregados, o que incluía o pagamento de salários muito baixos, e mais baixos ainda para mulheres, incentivava a emigração. A década de 1860 marcou o início da emigração de trabalhadores barbadianos para a Libéria e 
para a Guiana Inglesa, posteriormente estendendo essa emigração para países como Panamá, Costa Rica, Estados Unidos da América e para o Brasil, para onde uma das irmãs de Millie havia partido alguns anos antes da tragédia.

A emigração de mulheres era uma exceção à regra, visto que as companhias recrutadoras davam preferência aos homens entre 18 e 35 anos para contratos de trabalho. Além disso, no século $X X$ os contratos de trabalho eram prioritariamente voltados para o fornecimento de mão-de-obra para projetos de modernização como a construção de ferrovias, linhas de bonde, canais, eletrificação, telégrafo, e modernização de portos (HARPELLE, 2001). Para conseguirem um contrato de trabalho, homens deveriam comprovar experiência em trabalho similar e por volta de cinco anos de escolaridade (ROCHA e ALLEYNE, 2012).

No início do século XX não havia educação pública gratuita em Barbados, o que limitava o acesso à educação, pior ainda, as oportunidades de educação para meninas eram extremamente reduzidas, a não ser que as famílias tivessem dinheiro suficiente para pagar algumas das poucas escolas privadas. Nilza Menezes refere-se a mulheres imigrantes barbadianas que chegaram a Rondônia, na época da construção da ferrovia Madeira-Mamoré, que foram submetidas a prostituição, enquanto algumas encontraram emprego como lavadeiras na companhia construtora ou como empregadas domésticas para a elite estrangeira empregada no projeto. Maria Roseane Lima (2006) refere-se a essas imigrantes em Belém, muitas vivendo em condições precárias na segunda década do século $X X$, enquanto outras, com mais sorte, chegavam ao país sob o amparo legal e financeiro do casamento com barbadianos empregados oficialmente pelas empresas estrangeiras. Entre as mulheres que chegaram ao Brasil sem contrato de trabalho e que não se casaram, a maioria desapareceu (MENEZES, 1998). ${ }^{13}$ Teria sido este o caso da irmã de Millie, que diziam ter partido para o Brasil, e que segundo a patroa da vítima e sua irmã Clementina, nunca teria mandado notícias?

É compreensível se, de fato, Millie disse a James que queria partir de Barbados com destino ao Brasil. A possibilidade de partir trazia em si a promessa de uma nova vida, muito melhor do que aquela vivida em Barbados. A maior parte da população barbadiana não tinha muita informação sobre o Brasil, a não ser que era um lugar grande e longe, para o qual navios partiam de vez em quando. Em 1916, a "febre do Panamá" (termo usado para a emigração em massa de trabalhadores caribenhos que foram trabalhar na construção do canal), havia passado, e todos sabiam. A Guerra na Europa dificultava as migrações, e mesmo a emigração para o Brasil já havia declinado, depois da inauguração da grande ferrovia e do recuo nos investimentos internacionais por causa da Guerra.

A vida de Millie não apresentava nenhuma perspectiva de mudança drástica. 0 namorado não tinha condições financeiras para estabelecer família, emprego como doméstica era uma das poucas possibilidades de trabalho, o filho tinha que ser criado por outra mulher. Havia poucas perspectivas de melhoria no futuro, e o homem que dizia amá-la a tratava com rudeza, e a ameaçava de morte. Talvez Millie tenha achado que aquela fosse apenas mais uma ameaça, como tantas outras. 
O exame do corpo pelo perito mostrou que Millie foi morta pelas costas. Havia lacerações nos pulsos e mãos, e um pequeno corte, pouco profundo, entre uma das mãos e o pulso. Quando Joseph Gibson disse que vira Millie passar com as mãos para trás, seguida de perto por James, será que ela tinha os pulsos amarrados? Encontraram manchas de sangue pelo caminho: seriam do pulso dela? Mas por que ela não gritou, não pediu socorro? Seria por aceitar sua insignificância e impotência diante da situação? Ou teria esperança de que James mudasse de ideia no último momento?

O médico costatou vários cortes entre a orelha e o pescoço e nas costas, um corte de mais de $30 \mathrm{~cm}$ do pescoço até a coluna vertebral. A violência dos golpes afetou os ossos da cervical e da vertebral, a força utilizada nos golpes foi tal, que o médico levantou a hipótese de que um machado pudesse ter sido usado. Sabe-se pelo inquérito que James usou uma faca. Fica a possibilidade de que Millie estivesse no chão, de costas, no momento dos golpes, o que teria dado a James uma vantagem ao usar a pressão do próprio corpo nos golpes contra a namorada.

Ao final, a justiça foi feita. James Bayley foi condenado à forca pelo assassinato de Millicent Gittens. A história da morte de Millie se transformou em música e entrou para o folclore, viajando com outros emigrantes para outras ilhas e para o continente, onde grupos relembravam Barbados ao cantar alegres: "Millie Gone to Brasil”, em comunidades de imigrantes em Cuba ou na Costa Rica.

\section{O femicídio contra mulheres negras e o silêncio da historiografia}

O caso do assassinato de Helen Boxil não teve maiores repercussões na mídia. A violência contra as mulheres (e meninas) negras nas fazendas era parte do cotidiano de séculos, fato pouco discutido ou reconhecido pela elite local e tomado pelas vítimas como parte do peso de ser ou ter sido escrava. De certa forma, o crime cometido contra Helen, encontra-se na esfera do privado, pois aconteceu dentro do quarto que Helen ocupava na fazenda onde trabalhava, e o principal suspeito também era empregado da fazenda, ainda que hierarquicamente superior à vítima, já que o fato das fontes não indicarem que Fitzherbert era negro pode indicar que tratava-se de um empregado branco.

Já a morte de Millie, deu-se em espaço público, numa praia. Além disso, as testemunhas falam de encontros nas ruas e caminhos de Barbados. Homens e mulheres da comunidade participaram, de alguma forma, do desenrolar dos acontecimentos que levaram ao crime e depois, na sua elucidação. O jornal deu ampla cobertura e o assunto se tornou parte das memórias coletivas da ilha. Enfim, foi uma morte pública.

Assim como Helen, as condições econômicas e sociais em que Millie vivia, colocavam-na em posição vulnerável, potencial vítima de parceiros abusivos. Porém, há indícios de que a cultura do período tolerava a violência contra a mulher, dado reforçado na literatura de romances e na memória popular, tanto que no inquérito não houve perguntas sobre o caráter abusivo de James, ou sobre outros incidentes de violência entre o casal. 
Quando os estudos de Frantz Fanon são aplicados em análises de violência física e sexual contra o corpo da mulher negra fala-se de uma "castração" metafórica do homem negro, que tem sua masculinidade negada e atacada ao ser alvo direto da violência e ao ser impossibilitado de defender sua mulher e seus filhos e filhas dessa violência (FANON, 1967). Bell Hooks (1981) é uma das primeiras vozes a se levantar contra esta leitura, acusando o homem negro de ser conivente e cúmplice no abuso e na exploração das mulheres negras. Hooks denuncia o autoritarismo e o abuso dos homens negros para com as mulheres negras, ainda que não explore abertamente a questão da violência de gênero entre casais negros, ela explica que a obediência feminina e a possibilidade de oprimir a mulher e puni-la verbal e fisicamente por qualquer transgressão da norma patriarcal, revitaliza no homem sua posição de autoridade. Por outro lado, Fanon descreve como contato sexual com mulheres brancas, ainda que prostitutas, oferece ao antilhano uma confirmação de seu valor como homem (FANON 1967). Neste caso, conformar-se com a companheira negra se identifica com a aceitação de sua inferioridade e mais ainda, da inferioridade de sua companheira. Se utilizarmos tal conceito para analisarmos a raiva de James e seu propósito de matar Millie, encontramos o homem negro analfabeto, empobrecido, sem família e provavelmente ressentido de sua impotência.

James, aos 20 e poucos anos, era um empregado braçal numa destilaria de rum, tão pobre que não tinha calçado. Não há dados sobre sua família, mas o fato de que James, apesar de estar na idade mais produtiva não tenha emigrado e nem sido alistado como soldado para lutar em defesa da Inglaterra, na Primeira Guerra Mundial, faz supor que ele era analfabeto. Conforme já dito, os recrutadores para trabalho no estrangeiro e para o serviço militar davam preferência a candidatos mais fortes e com pelo menos cinco anos de educação. James era destituído de tudo o que era valorizado entre os homens. Sua masculinidade era atestada por seu relacionamento com Millie.

A vitimização de Millie oferece a James a confirmação de seu poder, como analisado por Michel Foucault (1997). Para Foucault uma das características do biopoder, está no poder que o soberano tem de matar ou deixar viver. Neste ato está o poder absoluto que confirma a autoridade soberana sobre o corpo daquela que está sujeita à sua autoridade. O cerne da teoria de Foucalt aplica-se à análise do poder do Estado sobre o indivíduo, podendo também ser utilizado para analisar o poder dos senhores de escravos sobre os corpos escravizados. Neste caso, teremos indivíduos situados na base da pirâmide social, econômica e política como alvos primordiais do biopoder. Porém, ao perceber-se como soberano de uma outra pessoa, no caso, sua amante, aquele que é alvo do poder soberano torna-se, ele mesmo o soberano de outrem, a quem pode matar e, dessa forma, confirmar sua autoridade. Pierre Bourdieu (2016) confirma a teoria de Foucault ao explorar as formas de dominação masculina comparando a masculinidade a uma nobreza. O poder de punir aquele que desafia a sua autoridade, transgressão para a qual, a pena máxima seria a morte. Ao sonhar em emigrar para o Brasil, Millie ameaçou a autoridade de James com a possibilidade de sair daquele relacionamento. 


\section{Considerações finais}

Ainda que seja sumamente importante a exploração do contexto histórico e das características do relacionamento de gênero dentro de um grupo específico, como os trabalhadores das classes mais baixas de Barbados no início do século XX, a essência do fato é a morte da mulher pelo simples fato dela ser mulher e, de alguma forma, desafiar o poder masculino ou, simplesmente, tornar-se o elemento que, com sua morte, viria a reforçar tal poder.

A história de gênero, tem sido revisada constantemente, com a inclusão de novos paradigmas como raça, geração, cultura, etnicidade, religião, sexualidade; pressionando para considerações especiais para contextos específicos como meios urbanos ou rurais, culturas de subalternidade, como as gangues, as prisões, as comunidades de imigrantes e tantas outras variantes. Longe de se atomizar o trabalho do historiador com divisões e subdivisões, entende-se que tais especificidades, ampliam a visibilidade de sujeitos em condição de subalternidade e em situações nas quais a generalidade acaba mascarando dados e reforçando sua invisibilidade.

Ao analisar o assassinato de Millie, tão importante quanto os detalhes do crime são as condições de vida de homens e mulheres afrodescendentes depois de quase 80 anos da abolição em Barbados ${ }^{14}$. A herança traumática da escravidão e a permanência de fatores de marginalização e subordinação têm um grande peso no comportamento agressivo de James e na passividade de Millie.

O fato de que a canção popular continue a ser cantada sem qualquer problematização de sua mensagem, aponta para a permanência de uma cultura que naturaliza a violência contra mulheres. Por outro lado, existe a continuidade de uma voz que por mais de 100 anos vem denunciando uma tragédia.

\section{Referências}

\section{Fontes Primárias}

BAILEY, Corin. Crime and violence in Barbados. IDB series on Crime and Violence in the Caribbean. Relatório Técnico, Junho, 2016. https://publications.iadb.org/bitstream/ handle/11319/7774/Crime-and-Violence-in-Barbados-IDB-Series-on-Crime-and-Violencein-the-Caribbean.pdf?sequence=1 Acesso em 12.07.2017.

Barbados Agricultural Reporter, 21 de abril, 1917.

Barbados Agricultural Reporter, 8 de dezembro de 1916.

Barbados Blue Books, Relatórios Anuais da colônia de Barbados. Barbados National Archives.

Official Gazette, April 23, 1917. 
The Agricultural Reporter, 05 de dezembro de 1916, p. 3. Tradução da autora.

The Agricultural Reporter, 17 de abril 1917.

UNWOMEN “Gender based violence in the Caribbean”. UNWomen. http://caribbean. unwomen.org/en/caribbean-gender-portal/caribbean-gbv-law-portal/gbv-in-thecaribbean\#sthash.jUOEVGPk.dpuf. Acesso em 12.07.2017.

\section{Bibliografia}

ABREU Martha. Sobre mulatas orgulhosas e crioulos atrevidos: conflitos raciais, gênero e nação nas canções populares (Sudeste do Brasil, 1890-1920). Tempo, n.16, p. 143-173, 2003.

AMADO, Jorge. Jubiabá. 37 ed. Rio de Janeiro: Record, 1978

AMADO, Jorge. Tereza Batista Cansada de Guerra. 12a ed. Rio de Janeiro: Record, 1978

AMADO, Jorge. Tieta do Agreste. 3a. ed. Rio de Janeiro: Record, 1978

APPLEWHAITE, Terry. Infant mortality in Barbados, 1850-1950: levels causes and official reaction. HISTORY FORUM, University of the West Indies, campus Cave Hill, Barbados, 02/11/2007.

ABANERJEE, S., CHATTERJII, A., CHAUDHRY, L., DESAI, M., TOOR, S., e VISWESWARAN, K. Engendering Violence: Boundaries, Histories, and the Everyday. Cultural Dynamics, v.16, n.2-3, 2004, p.125-139.

BARROS, Juanita de. Reproducing de British Caribbean. Sex, Gender and population after slavery. Chapel Hill: University of North Carolina Press, 2014.

BECKLES, Hilary. Great House rules: Landless emancipation and worker's protest in Barbados, 1838-1938. Kingston: Ian Randle, 2004.

BECKLES, Hilary. Property Rights in Pleasure: the marketing of enslaved women's sexuality. In: SHEPHERD, V. e BECKLES, H. Caribbean slavery in the Atlantic World. Kingston: Ian Randle, 2000, p. 692-701.

BESSE, Susan K. Crimes passionais: a campanha contra os assassinatos de mulheres no Brasil: 1910-1940". Revista Brasileira de História. v.9, n.18, p. 181-197, 1989.

BORELLI, Andrea. Matei por amor!: representação do masculino e do feminino nos crimes passionais - São Paulo nos anos 20 e 30. Dissertação (Mestrado em História), Pontifícia Universidade Católica de São Paulo, 1997.

BOURDIEU, Pierre. A dominação masculina. A condição feminina e a violência simbólica. Rio de Janeiro, Bestbolso, 2016.

BRODBER, Erna. The second generation of freeman in Jamaica, 1907-1944. Miami: Florida University Press, 2004. 
BROWN, Laurence e INNISS, Tara. Slave women, family strategies and the transition to freedom in Barbados, 1834-1841. In: CAMPBELL, G, MIERS, S. e MILLER, Joseph. Women and slavery. The modern Atlantic. Athen: Ohiao University Press, 2008, p. 172-85.

CHALHOUB, Sidney. Trabalho, lar e botequim, o cotidiano dos trabalhadores na Belle Époque. São Paulo: Brasiliense, 1986.

CORRÊA, Mariza. Morte em família: representações jurídicas de papéis sexuais. Rio de Janeiro: Graal, 1983.

EDWARDS, Rebecca. Women's and gender history. Washington: American Historical Association, 2012.

ENGEL, Magali. G. Paixão, crime e relações de gênero (Rio de Janeiro, 1890-1930). Topoi, v.1, p. 153-177, 2000. http://www.scielo.br/pdf/topoi/v1n1/2237-101X-topoi-1-01-00153. pdf Acesso em 10.07.2018.

EVARISTO, Conceição. Ponciá Vicêncio. 3 ed. Rio de Janeiro: Pallas, 2018.

FANON, Frantz. Black skin, white masks. New York: Grove Press, 1967,

FOUCAULT, Michel. Society must be defended. New York, Picador, 1997.

GRAHAM, Sandra .. Caetana diz não. Histórias de mulheres da sociedade escravista brasileira. São Paulo: Companhia das Letras, 2002.

HARPELLE, Ronald. The West Indians of Costa Rica: Race, Class, and the Integration of an Ethnic Minority. Montreal and Kingston: McGill-Queen's University Press, 2001.

HARTMAN, Sandra. Epistemological questions. In: HARTMAN, S. Feminism and methodology. Indianapolis: Indiana University Press, 1987, p. 181-190.

HILL COLLINS, Patricia. Black Feminist Thought: Knowledge, Consciousness, and the Politics of Empowerment. New York: Routledge, 2000.

HOOKS, Bell. Ain't I a woman. Black woman and feminism. Boston: South End Press, 1981.

INNISS, Tara. This complicated incest. Children, sexuality and sexual abuse during slavery and the apprenticeship period in the British Caribbean, 1790-1838. In: CAMPBELL, G. e ELBOURNE, E. Sex, power and slavery. Athens: Ohio University Press, 2014, p. 253-71.

JESUS, Carolina Maria de. Quarto de despejo. Diário de uma favelada. São Paulo: Ática, 2010.

JOSHER, Katharine. The case method in social research, Social Forces, n.2, v.7, p. 203-211, 1928.

KOZMA, Liat. Policing Egypcian women: sex law and medicine in Khedival Egypt. Syracuse: Syracuse University Press, 2011.

LAGARDE, Marcela. Del femicidio al feminicidio. Desde el Jardín de Freud, n. 6, p. 216-225, 2006. https://revistas.unal.edu.co/index.php/jardin/article/view/8343/8987 Acesso em 23.03.2019. 
LIMA, Maria Roseane Pinto de. Ingleses pretos, barbadianos negros, brasileiros morenos? Identidades e memórias (Belém, séculos XX e XXI). Tese (Doutorado em História), Universidade Federal do Pará, Belém, 2006.

MARSHALL, T., McGEARY, P e THOMPSON, G..Folk Songs of Barbados, Kingston:lan Randle Publishers, 1996.

MATOS DE CASTRO, Hebe. Das cores do silêncio. Os significados da liberdade no sudoeste escravista. Brasil sec XIX. Rio de Janeiro: Arquivo Nacional, 1995.

McGUIRE, Danielle. At the dark end of the street. Black women, rape and resistance - A new history of the Civil Rights Movement from Rosa Parks to the rise of Black Power. New York: Knopf, 2010.

MENEZES, Nilza. Chá das cinco na Floresta. Campinas: Comedy, 1998.

ROCHA, Elaine e ALLEYNE, Frederick. "Millie gone to Brazil: Barbadian migration to Brazil in the early 20th century". Journal of the Barbados Museum \& Historical Society, v. 58, p.1-42, 2012.

RODRIGUES DE SOUZA, M. Gênero, história e violência: casos de homicídio contra mulheres em Montes Claros - 1985 - 1993. OPSIS, v.11, n.1, p. 77-97, 2011.

RUSSELL, Diana. Defining Femicide. Discurso apresentado na abertura do Simpósio sobre Femicídio, das Nações Unidas em 26 de novembro de 2012. Disponível em http://www.dianarussell.com/f/Defining_Femicide_-_United_Nations_Speech_by_ Diana_E._H._Russell_Ph.D.pdf Acesso em 13.03.2019.

SHANGE, Ntozake. For colored girls who have considered suicide/when the rainbow is enuf. New York: Scribner, 2010.

SCOTT, Joan. Gender and the politics of history. Revised edition. New York: Columbia University Press, 1999.

SCOTT, Joan. The politics of the veil. Princeton: Princeton University Press, 2007.

SOIHET Rachel. "O corpo feminino como lugar da violência”. Projeto História, n.25, p. 269-89, 2002.

THORNTON DILL, Bonnie. The dialectics of Black womanhood. In: HARTMAN, S. Feminism and methodology. Indianapolis: Indiana University Press, 1987, p. 97-108.

VILLALÓN, Roberta. Passage to Citizenship and the Nuances of Agency: Latina Battered Immigrants. Women's Studies International Forum, v.33, n.6, p.552-560, 2010.

WALKER, Alice. The color purple.10 ed. Boston: Houghton Mifflin Harcourt, 1992.

WEST, Emily. Reflections on the History and Historians of the black woman's role in the community of slaves: enslaved women and intimate partner sexual violence. American Nineteenth Century History, v.19, n.1, p. 1-21, 2018. https://doi.org/10.1080/14664658.2 018.1429333 Acesso em 12.03.2019. 


\section{Notas}

1 Millie foi pro Brasil

Oh, Senhor, pobre Millie

Millie foi pro Brasil

Oh, Senhor, pobre Millie

com arame enrolado em volta da cintura

e um corte de navalha em seu rosto

com arame enrolado em volta da cintura

e um corte de navalha em seu rosto

Millie, lá em baixo no fundo do poço

Oh, Senhor, pobre Millie

Millie, lá em baixo no fundo do poço

Oh, Senhor, pobre Millie

com arame enrolado em volta da cintura

e um corte de navalha em seu rosto

com arame enrolado em volta da cintura

e um corte de navalha em seu rosto

Letra da música Millie Gone to Brazil, autoria desconhecida, conforme T. Marshall, P. McGeary, G. Thompson, Folk Songs of Barbados, Kingston: Ian Randle Publishers, 1996, p. 56. Tradução da autora.

2 "Gender based violence in the Caribbean". UNWomen. <http://caribbean.unwomen.org/en/caribbean-genderportal/caribbean-gbv-law-portal/gbv-in-the-caribbean\#sthash.jUOEVGPk.dpuf> Acesso em 12/07/2017.

$3 \mathrm{Na}$ economia açucareira barbadiana, a moradia do empregado rural estava assegurada por seu emprego na fazenda. Uma vez desempregado, este perderia tal direito, devendo retirar-se da propriedade. Esta prática contribuia para o controle da mão-de-obra, limitando o poder de barganha de trabalhadores, expondo famílias ao abandono e miséria. Para mais informações, ver BECKLES, Hilary. Great House rules: Landless emancipation and worker's protest in Barbados, 1838-1938. Kingston: Ian Randle, 2004.

4 De acordo com as estatísticas publicadas nos Barbados Blue Books, Relatórios Anuais da colônia de Barbados. Barbados National Archives.

5 Tradução da autora.

6 Barbados Agricultural Reporter, 21 de abril, 1917, p. 5.

7 Barbados Blue Books, 2017. Barbados National Archives.

8 Official Gazette, April 23, 1917, p. 821.

9 Official Gazette, April 23, 1917, p. 821. Tradução da autora.

10 Barbados Agricultural Reporter, 8 de dezembro de 1916, p.3-4. Tradução da autora.

11 The Agricultural Reporter, 17 de abril 1917, p. 3.

12 The Agricultural Reporter, 05 de dezembro de 1916, p. 3. Tradução da autora.

13 Entrevista de Nilza Menezes cedida a Elaine P. Rocha em 26/03/2013.

14 Nas colônias inglesas do Caribe, a escravidão foi abolida em 1834, estabelecendo-se um sistema de aprendizado que durou até 1837 , data da abolição definitiva do trabalho escravo. 
Elaine ROCHA é Doutora em História pela Universidade de São Paulo e Professora na University of the West Indies at Cave Hill, Bridgetown, Barbados. É autora de Mundos do trabalho e dos trabalhadores: experiências e vivências no Brasil e no Caribe. Rio de Janeiro: Multifoco, 2018; Another Black Like me: The Construction of Identities and Solidarity in the African Diaspora. Cambridge Scholars Publishing, 2015 e Racism in novels. A comparative study of Brazilian and South African Cultural history. Cambridge Scholars Publishing, 2010.

Recebido em: 30 março 2019 Aprovado em: 07 novembro 2019 